\title{
Historia de un despojo y de un litigio agrario: el caso de San José de Gracia y la presa Calles
}

\author{
História de uma desapropriação e de um litígio agrário: \\ o caso de San José de Gracia e a barragem Calles
}

\begin{abstract}
Jesús Antonio de la Torre Rangel
Profesor universitario, jurista e abogado en Aguascalientes, Doctorado en Filosofía por la Universidad Nacional Autónoma de México, Universidad Autónoma de Aguascalientes, Aguascalientes - México, e-mail: rangeljadelatorre@uuaa.mx
\end{abstract}

\section{Resumen}

Lo presente artículo trata de la cuestión de la disputa de tierras por parte de los indios de San José de Gracia, desde el embate con el propietario de la Hacienda de Paredes, bien como, posteriormente, hasta el inundamento de las tierras en consecuencia de la construcción de la presa Calles. El inundamento trajo como consecuencia la salida de los indios de su comunidad por medio de la expropiación. Los indios jamás recibieron indemnización y fueron dejados a su propia suerte. Aunque la administración pública federal haya prometido una compensación, ésta hasta hoy no ocurrió, haciendo con que se ingresase con una acción judicial. Más de 80 años después del ocurrido, los descendientes de aquel pueblo esperan por justicia y por la debida indemnización.

Palabras clave: Comunidad. Expropiación. Indemnización. 


\section{Resumo}

O presente artigo trata da questão da disputa de terras por parte dos índios de San José de Gracia, desde o embate com o proprietário da fazenda de Paredes, bem como, posteriormente, até o inundamento das terras em consequência da construção da barragem de Calles. $O$ inundamento trouxe como consequência a saída dos índios de sua comunidade por meio da expropriação. Os índios jamais receberam indenização e foram deixados à sua própria sorte. Embora a administração pública federal tenha prometido uma compensação, esta até hoje não ocorreu, fazendo com que se ingressasse com uma ação judicial. Mais de oitenta anos depois do ocorrido, os descendentes daquele povo esperam por justiça e pela devida indenização.

Palavras-chave: Comunidade. Expropriação. Indenização.

La escritora Carolina Castro Padilla, cuenta un cuento:

Aquí estamos, mujer, para hablar de nuestras cosas; ésas que sólo tú y yo entendemos. Aquí, bajo la sombra del atardecer mirando el agua de la presa con calma y en silencio. Que se quede allá el bullicio, en el centro del pueblo nuevo [...] (CASTRO PADILLA, [19--?]).

\section{La historia como fundamento de la acción restitutoria}

La comunidad o pueblo de indios de San José de Gracia existe, de hecho, desde 1675. Sin embargo, fue hasta el 9 de mayo de 1682 en que Juan Domínguez y otros once indios naturales y vecinos del pueblo otorgaron a Joseph Gómez de Santoyo poder para comparecer ante la Real Audiencia de la Nueva Galicia, con sede en Guadalajara, para que en su nombre pidiera licencia de la formación legal del propio pueblo o comunidad.

El poder se otorgó ante el escribano Alfonso de Navarrete y Argote y en el instrumento notarial expusieron: 
que ellos están ya más de siete años en su población, cada uno de jacales y corrales, en expuesto y sitio que llaman de Marta, en el Valle del Potrero, de esta jurisdicción, junto a un río que corre todo el año, distante de esta villa como seis leguas, y que los más de ellos siembran ahí sus milpas y tienen sus ganados mayores y menores y sus sitios de tierras... y pagan sus tributos a Su Majestad y diezmos a la Santa Iglesia, los cuales se hallan sin tierras propias para poder vivir con sus familias, y que para poderlas tener en propiedad por su Majestad necesitan de hacer pueblo en dicho puesto, iglesia como tienen otros naturales en los pueblos que viven... (SERRANO, 1992, p. 12).

Después de varios trámites antes la propia Audiencia de Nueva Galicia y pese al intento de esta autoridad colegiada de condicionar la autorización de la formación del pueblo si se establecía en otro lugar, mediante un auto fechado el 21 de enero de 1663, se facultó:

a los dichos naturales para que puedan fundar y funden el dicho Pueblo Nuevo con el asiento y nombre de San Joseph, en el puesto, sitio y parte donde han estado poblados y rancheados en dicha jurisdicción... fundándolo y fabricándolo en forma, y para que nombren y señalen los ministros y demás oficiales de la República según y en la forma que se acostumbra hacer en los pueblos fundados en este reino... les concedo dicha licencia y con tal que el dicho sitio referido fuere realengo, o teniendo dueño legítimo se entienda que los dichos naturales han de pagar su valor conforme se apreciare, y lo mismo se entienda si don Matías Carrasquilla verificara ser suyo dicho sitio... (SERRANO, 1992, p. 17).

Con esta autorización, el alcalde Verdín de Godar se presentó en el llamado Sitio de Marta, con el fin de darles posesión a los indios de las tierras y dejarlos asentados pacífica y legalmente. La ceremonia tuvo lugar el 8 de febrero de 1683. Congregados todos los indios o comuneros y tomados de las manos con los principales el Alcalde Mayor mencionado declaró, en nombre del rey que:

les daba y metía en posesión del dicho puesto y sitio de Marta y pueblo de San Joseph, con la distancia que en él se incluya y según costumbre 
de los demás pueblos, la cual les daba civil, actual y corporal, y como más a su derecho convenga... y los dichos naturales, a continuación y aprehensión de la posesión del dicho sitio y pueblo, se anduvieron paseando por el círculo y casas que en él tienen fabricadas de una parte a otra, tirando piedras y poniéndolas en otra parte, y arrancando terrones, y dijeron que tomaban y aprehendían la posesión de dicho sitio... Pasó todo lo dicho quieta y pacíficamente, sin contradicción de persona alguna que allí hubiere o pareciese, y su merced, dicho alcalde mayor, dijo que mandaba y mandó que los dichos naturales no sean desposeídos de la dicha posesión, de su pueblo, sitio y distancia que por él se incluirá, sin que primero sean oídos y por fuero y derecho vencidos, y que juntos y congregados según costumbre de los demás pueblos, hiciesen la elección de alcalde y demás oficiales y la presentasen ante su merced para con su aprobación entregarles la vara de la real justicia... (SERRANO, 1992, p. 18).

Es, pues, que desde el 8 de febrero de 1683 que los comuneros de San José de Gracia entraron en posesión, pacífica y legal, de sus tierras, siendo una fracción de las mismas en donde actualmente se encuentra edificada la presa constituye el Distrito de Riego Número Uno llamada Presidente Plutarco Elías Calles.

En virtud de la denuncia de bienes de realengo llevada a cabo por el propietario de la Hacienda de Paredes, ante la Audiencia de Nueva Galicia, se creó un conflicto con la comunidad de San José de Gracia por la disputa de los terrenos que ésta última mantenía en posesión, alegando los propietarios de la hacienda mencionada que se trataba de bienes de realengo y que debían ser adjudicados a su propietario formando parte de las tierras de la propia hacienda.

Lo anterior motivó que los comuneros de San José de Gracia se presentaran a defender los derechos sobre sus tierras ante la Real Audiencia del Reino de Nueva Galicia, solicitando un reconocimiento de todos los terrenos que alegaban les pertenecía a la propia comunidad, diciendo textualmente en su demanda de justicia: se sirva de adjudicarle todo y qualesquiera realengo que se comprehendiere en la antigua posesión que ha tenido. 
La Real Audiencia de Nueva Galicia, resolvió el litigio entablado entre los naturales del pueblo de San José de Gracia y Don José Antonio Hurtado dueño de la Hacienda de San José de Paredes, en los términos siguientes:

En su consecuencia acorde librar el presente por el cual usando de la facultad que me es conferida en nombre de su Majestad y sin perjuicio de su real derecho ni de el de otro tercero que mejor lo tenga hago adjudicación en forma a los naturales del Pueblo de San José de Gracia de dos sitios de ganado mayor que resultaron realengos, bajo los términos y linderos que quedan expresados para que como legítimos dueños de ellos mediante este título los usen y gocen como les convenga y por bien tuvieren poblándolos de ganados mayores, o menores, sembrándolos, cultivándolos, permutándolos, arrendándolos o vendiéndolos, como mejor les parezca bajo la precisa calidad de contenerse en los linderos referidos sin propasarse a ocupar más tierra de la que conforme a esta adjudicación les está concedida a cuyo fin mando pongan luego mojoneras de piedra y cal con asistencia del Juez Real del Partido y por presencia de los lindantes que hubiere en los límites asignados para que de esta suerte guarden la sujeción que se les previene en sus propios linderos. En inteligencia de que los han de tener poblados o en cualquiera otra forma ocupados con la labranza y crianza de ganados, y en el caso de ocupar alguna más tierra perteneciente al Real patrimonio han de hacer denuncia de ella dentro de tres meses primeros siguientes de como la ocupen para que igualmente se les mercene, y observando estas condiciones mando que los dos referidos sitios de ganado mayor sean de los indicados naturales del Pueblo de San José de Gracia y de sus sucesores y de los que su derecho representaren, y de la posesión en que se hallan, y de la que nuevamente aprehendieron en virtud de este título no sean despojados sin ser primero oídos y por fuero y derecho vencidos, ante quien con derecho pueda y deba (Texto de la Resolución de la Audiencia de Nueva Galicia, de 15 de diciembre de 1780).

Dado en Guadalajara a 15 de diciembre de 1780, la anterior resolución dictada por Don Joachin Cervera Enríquez, Presidente de la Real Audiencia de Nueva Galicia, que acabamos de describir, sirve, como reza 
el propio documento, de título primordial de los bienes comunales del pueblo San José de Gracia.

Dentro de esos dos sitios de ganado mayor referidos en el título que antecede, se asentó el fundo legal original del pueblo de San José de Gracia, esto es su asiento urbano.

Sigue contando Carolina Castro Padilla ([19-?]):

¿Te acuerdas cuando tu hermano Lorenzo trajo la noticia desde Aguascalientes? "Ora sí van a construir la presa", dijo bien contento, y tu papá se quedó muy serio y le puso su buena regañada. "De que se alegra tarugo, ¿qué no mira que nos van a perjudicar?”, empezó diciéndole, y luego siguió con todo aquello de que se iba a inundar el pueblo, que íbamos a perder nuestras tierras... que era el fin de todo.

Guardas silencio y vuelves a ver a aquel hombretón recio con sus ojos a la orilla del llanto, y recobras las platicas perdidas en el tiempo, que los hombres pronunciaron aquel fin de año de 1925, al amparo de un mezcal.

\section{La presa y el despojo}

A principios de 1926 se inició la construcción del Distrito de Riego Número Uno, que dio lugar a la Presa Presidente Plutarco Elías Calles, por parte de la hoy extinta Comisión Nacional de Irrigación, perteneciente a la Administración Pública Federal.

El sitio señalado para construir la cortina de hasta 63 metros de altura, que necesitó 46 mil metros cúbicos de cemento, se localizó en un cañón angosto y profundo que comunica al terreno de la mesa alta de San José de Gracia con el valle central del Estado de Aguascalientes, un poco abajo del asentamiento urbano original del pueblo de San José de Gracia a la entrada del cañón. Esta localización implicó inundar con sus aguas el asentamiento del pueblo.

En virtud, entonces, de que el vaso de la presa referida fue planeado para ocupar precisamente las tierras en donde se asentaba el antiguo fundo legal del pueblo de San José de Gracia, así como otras tierras 
pertenecientes a la propia comunidad, los antecesores, de los actuales comuneros, tuvieron que abandonar su pueblo hacia mediados de 1926.

De este modo la comunidad de San José de Gracia fue despojada de aproximadamente 1.500 hectáreas. Fue privada de la posesión del terreno referido sin haber sido oída ni vencida en juicio y sin mediar indemnización alguna proveniente de algún tipo de expropiación.

El despojo, desde entonces, ha sido permanente y continuado. La comunidad de San José de Gracia ha sido privada de la posesión de las hectáreas relacionadas desde entonces, y su derecho no ha sido reparado ni compensado en forma alguna.

Actualmente están en la posesión de esas tierras, órganos administrativos de la Federación, la Delegación en Aguascalientes de la Secretaría de Medio Ambiente y Recursos Naturales y el órgano administrativo desconcentrado llamado Comisión Nacional del Agua.

Y sigue su cuento Carito:

Tan re chulo que era nuestro Santuario. Su torre se divisaba desde lejos. Cuando salíamos a llevar el carbón a otros pueblos, ya de regreso, con sólo mirar la torre, se me quitaba el cansancio porque sabía que ya estaba en la casa. Por eso, cuando enpezó a llegar el agua y a inundar también el santuario, supe que todo estaba perdido. Nuestra parroquia erigida desde enero de 1769 estaba herida de muerte. (CASTRO PADILLA, [19--?]).

\section{El juicio de amparo}

Durante muchos años los comuneros recibieron promesas de la Administración Pública Federal, en el sentido de que se llevaría a cabo el trámite de expropiación de las tierras que ocupa la presa Calles, con el objeto de que la comunidad de San José de Gracia sea indemnizada. Han pasado más de 80 años de que se dio el despojo y no se ha hecho la expropiación.

Cansados los comuneros de recibir promesas decidieron, por fin, hacer uso de las instancias legales con el objeto de hacer valer sus derechos 
y de que se les haga justicia. Por esa razón promovieron un amparo agrario ante el C. Juez Tercero de Distrito en el Estado, expediente número $3 / 01$, con fecha 2 de enero del año 2001, alegando como acto reclamado la arbitraria e ilegal desposesión que hizo y ha mantenido el gobierno federal con relación a sus tierras. El Juez Tercero de Distrito en el Estado dictó sentencia, el 23 de abril del año 2001, estableciendo el sobreseimiento del juicio, argumentando que no se agotaron los recursos o medios de defensa antes del juicio de amparo.

Considerando que el Juez aludido no tomó en cuenta la excepción muy importante al principio de definitividad establecida en el párrafo $2^{\circ}$ de la Fracción XV del Articulo 73 de la Ley de Amparo, que establece que no existe obligación de agotar tales recursos o medios de defensa, si el acto reclamado carece de fundamentación, como es claramente el caso de esta desposesión, interpusieron el recurso de revisión el cual se tramitó ante el Tercer Tribunal Colegiado del vigésimo tercer circuito. Este Tribunal, desde nuestro punto de vista, forzando la interpretación, mantuvo el mismo criterio que el Juzgado de Distrito y confirmó la sentencia de primera instancia.

Reiteramos que se debió haber obtenido el amparo y protección de la Justicia Federal, porque la Comunidad de San José de Gracia fue privada de la posesión del terreno referido sin haber sido oída ni vencida en juicio y sin mediar indemnización alguna proveniente de algún tipo de expropiación; siendo el acto arbitrario, carente de toda fundamentación.

\section{El juicio agrario de restitución}

En virtud de que, por vía de amparo, los comuneros no obtuvieron la recuperación de sus tierras, recurrieron entonces a un juicio agrario restitutorio. De tal modo que Felipe Ventura Rodríguez, J. Felix Rodríguez Cardona y J. Jesús González Quiroz, en su carácter de Presidente, Secretario y Tesorero, respectivamente, del Comisariado de Bienes Comunales de San José de Gracia, demandaron a la Secretaría de Medio Ambiente y Recursos 
Naturales y a la Comisión Nacional del Agua en Aguascalientes, por la restitución de las tierras que ocupa la presa Calles. La demanda se entabló ante el Tribunal Unitario Agrario del Primer Distrito, sede alterna en Aguascalientes, correspondiéndole como número de expediente el 128/2001.

El juicio agrario siguió su secuela procesal. La parte demandada, esto es, la Federación, contestó la demanda; se desahogaron pruebas y las partes alegaron. Se dictó sentencia con fecha de 1 de octubre de 2002, en la que el Tribunal Unitario Agrario resolvió declarando improcedente la acción de restitución de tierras comunales promovidas por los comuneros de San José de Gracia y que la parte demandada justificó sus defensas y excepciones, absolviéndola de todas y cada una de las prestaciones reclamadas.

Inconforme con el fallo, la Comunidad de San José de Gracia interpuso recurso de revisión en contra de la sentencia, para que se sustanciara ante el Tribunal Superior Agrario.

El Tribunal Superior Agrario revocó la sentencia de primera instancia, sin entrar al conocimiento del fondo, esto es, sin atender los agravios hechos valer por los comuneros; ya que ordenó se repusiera el procedimiento mandando el desahogo de una pericial y que se informara del estado que guardaba el procedimiento de expropiación que había iniciado la Secretaría de la Reforma Agraria. A pesar de que esos agravios no fueron atendidos en ese momento, a final de cuentas constituyen los fundamentos y argumentos de la segunda sentencia dictada por el Tribunal Unitario Agrario, una vez que se desahogó la pericial ordenada por el Superior y se llevaron a cabo las otras diligencias. Por lo tanto, conviene hacer una síntesis de los mismos, ya que constituyen el aspecto jurídico más relevante de este litigio.

\section{Agravios}

Los agravios fueron formulados por los comuneros del modo siguiente: 
La sentencia recurrida causa agravios a la Comunidad de San José de Gracia, por diversas razones. Si bien el artículo 189 de Ley Agraria establece que las sentencias de los Tribunales Agrarios se dictarán a verdad sabida sin necesidad de sujetarse a reglas sobre estimación de las pruebas, sino apreciando los hechos y los documentos según los propios tribunales lo estimaren debido en conciencia, esto no significa que las sentencias puedan ser arbitrarias.

En el caso que nos ocupa, la sentencia dictada por el Tribunal Unitario Agrario del Distrito Uno, sede alterna en Aguascalientes, en la controversia por restitución de tierras comunales de San José de Gracia, es arbitraria. Esto en virtud de que la resolución analiza los hechos parcialmente, distorsiona principios básicos del derecho agrario y contraría principios elementales de la razón.

Luego se cita una tesis de un tribunal colegiado y se comenta de este modo:

De acuerdo a esta tesis jurisprudencial, es muy claro que el juzgar y valorar las pruebas a verdad sabida, no significa que los Magistrados de los Tribunales Agrarios valoren y juzguen como les venga en gana, sino que deben guardar dos principios generales del derecho: la buena fe y la equidad. Y juzgar y valorar las pruebas guardando los principios de buena fe y equidad, implica no distorsionar o ver sólo parcialmente los hechos, no torcer el derecho y utilizar la razón. En concreto, la equidad es la aplicación concreta de la justicia y significa una corrección de la ley con un sentido jurídico profundo; queremos decir que juzgar con equidad significa juzgar en derecho, que quiere decir que a verdad sabida se entiende que implica la equidad; los Tribunales Agrarios no pueden apartarse de lo jurídico para emitir sus resoluciones. En el caso concreto, nos causa agravio la sentencia precisamente porque se aparta de los principios jurídicos relativos a la materia agraria.

\section{Y continúan los comuneros:}

Una vez que ha hecho el análisis de las pruebas ofrecidas por las partes, la Magistrada resolutora emite su juicio y establece que "estima es improcedente la acción restitutoria incoada por el poblado de San José de 
Gracia”, y a continuación establece los argumentos que la llevan a esa conclusión. Comienzan por establecer los elementos que deben acreditarse para la procedencia de una acción restitutoria, los cuales son los siguientes, mencionados por la propia juzgadora: “a).- La propiedad de las tierras que reclaman; b).- La posesión por parte del demandado de la cosa perseguida; y c).- La identidad de la misma, es decir que no pueda dudarse cuál es la cosa que el actor pretende se le restituya y a la que se refieren los documentos fundatorios de la acción." Tales elementos los desprende de una jurisprudencia que cita en la propia sentencia.

Para demostrar la procedencia de los agravios, en primer lugar establecieron porque sí quedaron debidamente probados en autos los elementos de la restitución, y en segundo lugar desvirtuaron la argumentación que sostiene que tales elementos no se probaron.

La propiedad de las tierras que se reclaman, esto es la titularidad de la superficie reivindicada, se acreditó con los siguientes elementos probatorios:

a) la documental pública consistente en la copia certificada de la resolución dictada por la Audiencia de Nueva Galicia que constituye el título primordial de bienes comunales del pueblo de indios o Comunidad de San José de Gracia;

b) la documental pública consistente en la copia certificada por el Coordinador Agrario en el Estado de Aguascalientes de la Secretaría de la Reforma Agraria de la Resolución Presidencial de fecha 10 de marzo de 1954 relativa a la confirmación y titulación de bienes comunales de San José de Gracia;

c) la documental consistente en la copia del Diario Oficial de la Federación de 14 de septiembre de 1954 en la que se publica la resolución sobre Confirmación y Titulación de terrenos comunales de San José de Gracia;

d) la documental pública consistente en copia certificada del Acta de Posesión y Deslinde relativa a la Confirmación y Titulación de terrenos comunales de San José de Gracia, de fecha 10 de marzo de 1954; 
e) la documental pública consistente en el Acta de Deslinde y Amojonamiento relativa a los terrenos correspondientes a la Confirmación y Titulación de Bienes Comunales de la Comunidad Indígena "San José de Gracia", de fecha 18 de junio de 2000;

f) la prueba documental consistente en una copia del plano informativo para la elaboración del plano definitivo de titulación de terrenos comunales para el poblado de San José de Gracia;

g) la prueba documental pública consistente en el oficio número BOO.E.41. 0.2.98/090877, de la Comisión Nacional del Agua, Gerencia Estatal de Aguascalientes suscrito por el Ingeniero Martín Molina Ochoa, en su carácter de Gerente Estatal y dirigido al C. José González Quiroz, Presidente de Bienes Comunales del poblado de San José de Gracia de fecha uno de abril de mil novecientos noventa y ocho en donde le anexa el oficio número 0369 de 30 de enero de 1998, de la secretaria del Medio Ambiente, Recursos Naturales y Pesca, dirigido a Arturo Warman, secretario de la Reforma Agraria, solicitándole la expropiación de los terrenos en donde se encuentra la presa Plutarco Elías Calles;

h) la documental consistente en un documento interno del Departamento Agrario de 5 de septiembre de 1934 en el que el encargado del Despacho del propio Departamento y Secretario General del mismo, instruye a la Sección de Fomento Ejidal de la propia Institución en el modo en que deben compensarse y la procedencia de expropiación de las tierras de la Comunidad de San José de Gracia en donde se encuentra la presa Plutarco Elías Calles.

Con todas y cada una de las pruebas documentales arriba relacionadas, se encuentra probado en autos la propiedad o dominio, esto es la titularidad de las tierras cuya restitución se reclama por parte de la Comunidad de San José de Gracia.

"La primera documental arriba mencionada lo es la resolución dictada por la Audiencia de Nueva Galicia resolviendo un litigio entablado 
entre la Comunidad de San José de Gracia y el señor José Antonio Hurtado, dueño de la hacienda de San José de Paredes, que constituye un título primordial de bienes comunales del propio pueblo de indios o Comunidad de San José de Gracia. Esto en virtud de que el máximo tribunal novohispano en la jurisdicción de Nueva Galicia, a la que pertenecía la Comunidad de San José de Gracia, en la resolución mencionada, establece que usando de la facultad que le es conferida en nombre de su Majestad hace adjudicación en forma a los naturales del pueblo de San José de Gracia de dos sitios de ganado mayor, para que como legítimos dueños de ellos 'mediante este título los usen y gocen como les convenga y por bien tuvieren poblándolos de ganados mayores, o menores, sembrándolos, cultivándolos, permutándolos, arrendándolos o vendiéndolos, como mejor les parezca'; y se agrega que los dos referidos sitios de ganado mayor sean de los naturales del pueblo de San José de Gracia y de sus sucesores y de los que su derecho representaren y que por ese título 'no sean despojados sin ser primero oídos y por fuero y derecho vencidos"”.

"La autenticidad de esta resolución que tiene el carácter de título primordial de las tierras pertenecientes a la Comunidad de San José de Gracia, fue declarada por la Sección de Paleografía de la Oficina Jurídica del Departamento Agrario, dentro de la tramitación del expediente agrario que dio lugar a la Resolución sobre Confirmación y Titulación de terrenos comunales del pueblo o Comunidad de San José de Gracia según Resolución Presidencial de diez de marzo de mil novecientos cincuenta y cuatro y publicada en el Diario Oficial de la Federación de catorce de septiembre de mil novecientos cincuenta y cuatro".

"La Comunidad o pueblo de indios de San José de Gracia tiene existencia de derecho desde fines del siglo XVII, en que la Audiencia de Nueva Galicia dio la autorización para la fundación del pueblo y les dio a los comuneros la posesión de sus tierras. De no haber sido así, esto es de no haber tenido existencia jurídica no se le hubiese reconocido personalidad alguna en el litigio en contra de la Hacienda de Paredes y no se hubiera dictado resolución favorable al propio pueblo de indios ni se le hubieran adjudicado la tierras que hemos mencionado por la propia 
autoridad judicial novohispana, el quince de diciembre de mil setecientos ochenta, aproximadamente a un siglo de que había sido autorizada su fundación y se les había dado formalmente posesión de las tierras que la propia comunidad había adquirido".

"Por lo anterior resulta absurdo, de mala fe e inequitativo - decían los comuneros en su escrito de agrários - que en la sentencia recurrida no se valore debidamente la resolución dictada por la Audiencia de Nueva Galicia de quince de diciembre de mil setecientos ochenta al establecerse que lo que se prueba es que "la comunidad de referencia existe de hecho desde la fecha mencionada, sin embargo, no es apta para acreditar la titularidad de la superficie que es materia del juicio, y en la cual se localiza la presa de almacenamiento denominada Plutarco Elías Calles, ello es así, porque esta obra hidráulica se construyó en el año de mil novecientos veintiséis como lo reconocen las partes en sus libelos de demanda y de contestación a la misma... es decir, que la construcción de la obra hidráulica se verificó cuando la comunidad demandante no existía de derecho...' (foja trece de la sentencia). La Comunidad de San José de Gracia, como lo demuestran los documentos aludidos, no sólo ha tenido, desde fines del siglo XVII, existencia de hecho sino también y plenamente de derecho. El derecho, el gobierno y las instituciones novohispanas reconocieron la personalidad jurídica y la propiedad de los pueblos indios. Al darse la independencia, al transformarse la Nueva España en México no hubo una creación del nuevo Estado de la nada, por lo que no hubo un cambio jurídico e institucional radical y absoluto. Hubo transformaciones, es cierto, pero se fueron haciendo paulatinamente. Los que tenían personalidad jurídica o los propietarios no dejaron de tener personalidad jurídica ni dejaron de ser propietarios con la firma de los Tratados de Córdoba o con la entrada del Ejército Trigarante a la ciudad de México; de tal modo que el veintiocho de septiembre de mil ochocientos veintiuno, un día después de consumada la independencia de México, los comuneros de San José de Gracia no dejaron de tener existencia de derecho ni dejaron de ser propietarios de sus tierras".

"A mediados del siglo XIX, la Reforma implicó, desde su perspectiva individualista liberal, cambios muy importantes en el derecho, que 
afectaron a comunidades y pueblos de indios. Muchos de estos perdieron sus tierras, siendo así despojados jurídicamente, y en general se interpretó que los pueblos y comunidades habían sido disueltos y por lo tanto carecían de existencia y, por supuesto, de personalidad jurídica. Todo esto en virtud de la aplicación de la Ley de Desamortización de Bienes del veinticinco de junio de mil ochocientos cincuenta y seis".

"Del tal modo, pues, que en el transcurso de toda la mitad del siglo XIX y la primera década del XX, por la interpretación que se hizo en el sentido de que las comunidades indígenas eran corporaciones civiles que tenían bienes inmuebles amortizados, se entendió que debían extinguirse y, por lo tanto, que los bienes inmuebles que tenían en propiedad como son sus tierras, debían privatizarse ya sea adjudicándose a sus arrendatarios, ya sea rematándose en pública subasta o bien adjudicándose por parcelas en propiedad privada a lo propios miembros de la comunidad".

"El movimiento político, militar y jurídico conocido como Revolución Mexicana, tuvo como una de sus principales banderas la reforma agraria. En efecto, la aplicación de la Ley de Desamortización así como otras leyes relativas a terrenos baldíos, originaron el gran latifundismo mexicano, pues muchas comunidades indígenas y pequeños propietarios pobres perdieron sus tierras, concentrándose estas en pocas manos, provocándose un gran movimiento social que pronto se expresó también jurídicamente con diversas leyes agrarias y el texto original del artículo 27 de la Constitución Política de los Estados Unidos Mexicanos de 1917".

"La primera ley agraria que restablece el reconocimiento tanto de la existencia como de la personalidad jurídica de las comunidades indígenas, lo fue la Ley del seis de enero de mil novecientos quince, expedida por el Primer Jefe del Ejército Constitucionalista encargado del Poder Ejecutivo de los Estados Unidos Mexicanos y Jefe de la Revolución en virtud de las facultades de que estaba investido. Y de acuerdo con esta ley, los pueblos y comunidades de indios no sólo fueron reconocidos en su existencia y personalidad, sino que además se restableció su capacidad para ser propietarios de bienes inmuebles e incluso para que se les restituyeran las tierras que habían perdido". 
“El artículo 27 de la Constitución Política de los Estados Unidos Mexicanos en su texto original recoge los principios fundamentales de la ley del seis de enero de mil novecientos quince y profundiza la reforma agraria, consolidando los derechos de los pueblos y comunidades indígenas a la tierra".

"La Comunidad de San José de Gracia no sufrió afectación por la Ley de Desamortización mencionada, pues sus tierras siguieron en posesión de toda la comunidad. Y bien, si acaso se llegó a interpretar que carecía de existencia jurídica por la vigencia de las leyes de reforma, su existencia de derecho y su personalidad jurídica la recobró con la expedición de la Ley de seis de enero de mil novecientos quince, normatividad que nulificó y dejó sin efectos los actos perjudiciales a las comunidades indígenas de la Ley de Desamortización del veinticinco de junio de mil ochocientos cincuenta y seis".

"Si esto es así, la propiedad de las tierras de la Comunidad de San José de Gracia, en donde se encuentra construida la presa Presidente Plutarco Elías Calles, se ha conservado en el dominio del propio pueblo de indios mencionado, desde que fueron adquiridas a fines del siglo XVII, obteniendo título primordial a fines del siglo XVIII, y hasta la fecha en que no ha habido expropiación alguna. De tal modo que cuando en mil novecientos veintiséis se construyó, en el mismo fundo legal del pueblo de San José de Gracia y en varios de sus terrenos de cultivo, la presa Calles del Distrito de Riego 01, la Comunidad de San José de Gracia tenía plena existencia jurídica y era, como sigue siendo, propietaria de las tierras cuya restitución se reclama”.

Es claro, entonces, el agravio que causaba la resolución recurrida a la Comunidad de San José de Gracia pues violaba además la jurisprudencia dictada por la Segunda Sala de la Suprema Corte de Justicia de la Nación.

A continuación se cita en los agravios; no los aburro con su lectura, pero sí les digo que es fundamental para entender el derecho agrario mexicano:

AGRARIO. COMUNIDADES DE HECHO Y DE DERECHO. PERSONALIDAD. En relación con la distinción entre comunidades de hecho 
y de derecho, y comunidades, verdaderas copropiedades sujetas al derecho civil, cabe efectuar las siguientes consideraciones: la propiedad de los indios sufrió muchos ataques a partir de la conquista española, pero, al decir de algunos historiadores, la propiedad más respetada fue la que pertenecía a los barrios (calpulli), propiedad comunal de los pueblos. Sin embargo, cuando se empezó a legislar sobre la propiedad, se ordenó respetar la de los indios, y, por medio de varias disposiciones, se procuró organizarla sobre las mismas bases generales que la sustentaban antes de la conquista, a saber, en la forma de propiedad comunal. La mayor parte de la propiedad de los pueblos indígenas quedó, por tanto, como en la época precolonial. Algunos de esos pueblos vieron confirmada su posesión inmemorial, anterior a la colonia, por los reyes de España, durante el virreinato; otros recibieron tierras por orden de dichos monarcas, durante el gran proceso de concentración de los indios dispersos, en pueblos, que se efectuó en cumplimiento, entre otras, de las cédulas de 21 de marzo de 1551 y 19 de febrero de 1560. En la Ley de 6 de enero de 1915, promulgada por Venustiano Carranza, uno de los considerandos decía: "Que según se desprende de los litigios existentes, siempre han quedado burlados los derechos de los pueblos y comunidades, debido a que, careciendo ellos, conforme al artículo 27 de la Constitución Federal, de capacidad para adquirir y poseer bienes raíces, se les hacía carecer también de personalidad jurídica para defender sus derechos". En la 61a. sesión ordinaria del Congreso Constituyente de Querétaro, celebrada la tarde del jueves 25 de enero de 1917, se presentó una iniciativa, suscrita por varios diputados, referente a la propiedad en la República. Entre los párrafos importantes de la exposición de motivos de la iniciativa, se encuentran los que a continuación se transcriben: "Los derechos de dominio concedidos a los indios, eran alguna vez individuales y semejantes a los de los españoles, pero generalmente eran dados a comunidades y revestían la forma de una propiedad privada restringida. Aparte de los derechos expresamente concedidos a los españoles y a los indígenas, los reyes, por el espíritu de una piadosa jurisprudencia, respetaban las diversas formas de posesión de hecho que mantenían muchos indios, incapaces, todavía, por falta de desarrollo evolutivo, de solicitar y de obtener concesiones expresas de derechos determinados. Por virtud de la Independencia se produjo en el país una reacción contra todo lo tradicional y por virtud de ella se adoptó una legislación civil incompleta, porque no se refería más que a la propiedad plena y perfecta, tal cual se 
encuentra en algunos pueblos de Europa. Esa legislación favorecía a las clases altas, descendientes de los españoles coloniales, pero dejaba sin amparo y sin protección a los indígenas. Aunque desconocidas por las leyes desde la Independencia, la propiedad reconocida y la posesión respetada de los indígenas, seguían, si no de derecho, sí de hecho, regidas por las leyes coloniales; pero los despojos sufridos eran tantos, que no pudiendo ser remediados por los medios de la justicia, daban lugar a depredaciones compensativas y represiones sangrientas. Ese mal se agravó de la Reforma en adelante, porque los fraccionamientos obligados de los terrenos comunales de los indígenas, sí favorecieron la formación de la escasa propiedad pequeña que tenemos, privó a los indígenas de nuevas tierras, puesto que a expensas de las que antes tenían, se formó la referida pequeña propiedad. Precisamente el conocimiento exacto de los hechos sucedidos, nos ha servido para comprender las necesidades indeclinables de reparar errores cometidos. Es absolutamente necesario que en lo sucesivo nuestras leyes no pasen por alto los hechos que palpitan en la realidad, como hasta ahora ha sucedido, y es más necesario aun que la ley constitucional, fuente y origen de todas las demás que habían de dictarse, no eluda, como lo hizo la de 1857, las cuestiones de propiedad, por miedo a las consecuencias. Así, pues, la nación ha vivido durante cien años con los trastornos producidos por el error de haber adoptado una legislación extraña e incompleta en materia de propiedad, preciso será reparar ese error para que aquellos trastornos tengan fin. Volviendo a la legislación civil, como ya dijimos, no conoce más que la propiedad privada perfecta; en los códigos civiles de la República apenas hay una que otra disposición para las corporaciones de plena propiedad privada permitidas por las leyes constitucionales: en ninguna hay una sola disposición que pueda regir ni la existencia, ni el funcionamiento, ni el desarrollo de todo ese mundo de comunidades que se agita en el fondo de nuestra Constitución social: las leyes ignoran que hay condueñazgos, rancherías, pueblos, congregaciones, tribus, etcétera; y es verdaderamente vergonzoso que, cuando se trata de algún asunto referente a las comunidades mencionadas, se tienen que buscar las leyes aplicables en las compilaciones de la época colonial, que no hay cinco abogados en toda la República que conozcan bien. En lo sucesivo, las cosas cambiarán. El proyecto que nosotros formulamos reconoce tres clases de derechos territoriales que real y verdaderamente existen en el país; la de la propiedad privada plena, que puede tener sus dos ramas, o sea la individual y 
la colectiva; la de la propiedad privada restringida de las corporaciones o comunidades de población y dueñas de tierras y aguas poseídas en comunidad; y la de posesiones de hecho, cualquiera que sea el motivo y condición. A establecer la primera clase van dirigidas las disposiciones de las fracciones I, II, III, V, VI y VII de la proposición que presentamos; a restablecer la segunda van dirigidas las disposiciones de las fracciones IV y VIII; a incorporar la tercera con las otras dos van encaminadas las disposiciones de la fracción XIII. La iniciativa anteriormente citada, previo dictamen y discusión, se aprobó con modificaciones y pasó a ser el artículo 27 de la nueva Constitución. La fracción IV de la iniciativa pasó a ser la fracción VI del texto, que fue aprobado en los siguientes términos: "VI. Los condueñazgos, rancherías, pueblos, congregaciones, tribus y demás corporaciones de población, que de hecho o por derecho guarden el estado comunal, tendrán capacidad para disfrutar en común las tierras, bosques y aguas que les pertenezcan o que se les hayan restituido o restituyeren, conforme a la ley de 6 de enero de 1915, entre tanto la ley determina la manera de hacer el repartimiento únicamente de las tierras". Mediante reforma publicada en el Diario Oficial del 10 de enero de 1934, la fracción VI paso a ser fracción VII con la siguiente redacción: "VII. Los núcleos de población que de hecho o por derecho guarden el estado comunal, tendrán capacidad para disfrutar en común las tierras que les pertenezcan o que se les hayan restituido o restituyeren". En el dictamen emitido por las Comisiones Unidas, 1a. Agraria, 2a. De Puntos Constitucionales y 1a. de Gobernación y presidente de la Gran Comisión de la Cámara de Diputados, únicamente se dice que ya es tiempo de buscar una redacción definitiva del artículo 27 constitucional y que "el punto de categoría política, por ejemplo, ha quedado totalmente eliminado, y en el texto que hoy se propone se habla genéricamente de núcleos de población, en lugar de hacer la enumeración, posiblemente restrictiva, de pueblos, rancherías, etcétera". En la reforma publicada en el Diario Oficial del 6 de diciembre de 1937, la fracción VII del artículo 27 constitucional se adicionó y desde esa fecha ha tenido la misma redacción. Los breves datos históricos y jurídicos aquí expuestos, en punto a las comunidades indígenas, permite concluir que por comunidad de derecho el Constituyente quiso referirse a aquellos grupos de indígenas que vieron confirmada su posesión por los reyes de España durante la época colonial, o que recibieron tierras durante el proceso de concentración de los indios dispersos, en pueblos, durante dicha época, o que por cualquier 
otro título tuvieran reconocido su derecho a determinadas tierras, bosques y aguas; y atribuyó existencia jurídica a las comunidades de hecho, al reconocerles existencia jurídica constitucional a las posesiones respetadas por los monarcas españoles, aun cuando no tuvieran título, o a aquellas posesiones que a partir de la conquista adquirieron algunos pueblos. Y por último, el aceptar la tesis de una tercera categoría de comunidades, sin personalidad para comparecer ante una autoridad judicial, es regresar al estado que guardaban las comunidades en el periodo comprendido entre la consumación de la Independencia y la Constitución de 1917 y que se agravó por la ley de 25 de junio de 1856. Finalmente, el artículo 27, fracción VII, constitucional, reconoce personalidad jurídica a los núcleos de población que de hecho o por derecho guarden el estado comunal, sin hacer distinción entre los que tengan títulos coloniales o de la época independiente y los que no tengan título, y si la norma fundamental no distingue, el intérprete tampoco puede hacer distinción.

Séptima Epoca, Segunda Sala de la SCJN, Semanario Judicial de la Federación, Tomo 91-96 tercera parte, página 109.

Volumen 34, página 15. Amparo en revisión 68/71. J. Isabel Lara Velázquez y otro. 11 de octubre de 1971. Unanimidad de cuatro votos. Ponente: Carlos del Río Rodríguez.

Volumen 46, página 17. Amparo en revisión 2506/72. Mancomunidad del Rancho de "Los Ruices", Municipio Dr. Belisario Domínguez, Chihuahua. 13 de octubre de 1972. Unanimidad de cuatro votos. Ponente: Jorge Iñárritu.

Volumen 75, página 15. Amparo en revisión 4079/74. Andrés Antelo Esquer y otros. 13 de marzo de 1975. Unanimidad de cuatro votos. Ponente: Carlos del Río Rodríguez.

Volúmenes 91-96, página 18. Amparo en revisión 4878/74. Jesús Alvidres Vitolas y otros. 30 de agosto de 1976. Unanimidad de cuatro votos. Ponente: Antonio Rocha Cordero.

Volúmenes 91-96, página 18. Amparo en revisión 3437/73. Juan Gutiérrez Anguiano y coagraviados. 9 de septiembre de 1976. Unanimidad de cuatro votos. Ponente: Carlos del Río Rodríguez. 
Nota: en el Apéndice 1917-1985, página 83, la tesis aparece bajo el rubro COMUNIDADES AGRARIAS DE HECHO Y DE DERECHO. PERSONALIDAD.

En el Informe de 1976, la tesis aparece bajo el rubro COMUNIDADES AGRARIAS DE HECHO Y DE DERECHO. PERSONALIDAD DE LAS.

La formulación del anterior agravio, consideramos que basta y sobra para demostrar lo arbitrario de la sentencia recurrida y la propiedad o dominio que tiene la Comunidad de San José de Gracia sobre las tierras que ocupa la presa Calles. Se formularon otros, pero por cuestiones de tiempo ya no me referiré a ellos.

Y continúa el cuento de Carolina Castro:

Al subir el agua, el pueblo era ya como un fantasma y ¿sabes de qué me acuerdo mujer? De aquellos hombres que no querían salirse del pueblo; estaban allí como clavados, en silencio y con los ojos fijos en la lejanía. Y allí se habrían quedado de no ser porque llegaron las autoridades y a fuerza los subieron a una lancha y los arrimaron a la orilla. Luego se quedaron allí parados mirando el desastre entre el temblor de su llanto. Esos, ya nunca pudieron mirar a otro lado, sólo a su recuerdo, como yo pues (CASTRO PADILLA, [19--?]).

\section{Segunda Sentencia del Tribunal Unitario Agrário}

Una vez desahogada la pericial topográfica ordenada por el Tribunal Superior Agrario, e informado que el procedimiento expropiatorio instaurado por la Secretaría de la Reforma Agraria estaba suspendido en espera de la resolución del juicio agrario, se consideró concluido el procedimiento. Y así, con fecha 18 de octubre de 2007, el magistrado Juan Rodolfo Lara Orozco - titular distinto al que dictó la primera sentencia -, dictó resolución estableciendo que la comunidad accionante denominada "San José de Gracia”, acreditó los extremos constitutivos de sus pretensiones, y los demandados Secretaría de Medio Ambiente y Recursos Naturales y la Comisión Nacional del Agua, no justificaron sus excepciones y defensas. 
La sentencia del Tribunal Unitario Agrario, en algunos de sus aspectos fundamentales dice:

OCTAVO - Del análisis y valoración de las pruebas aportadas al sumario en conciencia y a verdad sabida, en los términos del artículo 189 de la Ley Agraria, este Tribunal llega a la plena convicción de que la comunidad accionante acreditó los extremos constitutivos de sus pretensiones, en tanto, que los demandados Secretaría de Medio Ambiente y Recursos Naturales y Comisión Nacional del Agua, no justificaron sus excepciones y defensas, todo ello en atención a las siguientes consideraciones. En efecto, la comunidad accionante a la luz de la resolución emitida por el juez privativo de ventas y composiciones de tierras, del entonces Reino de la Nueva Galicia, con sede en Guadalajara, el quince de diciembre de mil setecientos ochenta, acreditaron fehacientemente que les fueron adjudicadas a los naturales del pueblo de San José de Gracia, de la jurisdicción de la Villa de Aguascalientes, dos sitios de ganado mayor, que resultaron realengos, para que como legítimos dueños, mediante ese título, usaran y gozaran de ellos, como mejor les conviniera y por bien tuvieren los poblaran con ganado, los sembraran, cultivaran, arrendaran o vendieran como mejor les pareciera, bajo la precisa calidad de contenerse a sus linderos sin propasarse a ocupar más tierras que conforme a la adjudicación les fuere concedida; asimismo, que se trata en origen de una comunidad indígena de derecho, a la que le fue reconocida la propiedad de sus posesiones por título virreynal cuya personalidad jurídica y propiedad está protegida íntegramente de acuerdo por la fracción VII del artículo 27 Constitucional, en relación con el 99 de la Ley Agraria.

Tiene aplicación al caso, la Jurisprudencia aprobada por la anterior integración de la Segunda Sala del más alto Tribunal de Justicia en nuestro País, consultable en el Semanario Judicial de la Federación, Volumen 91-96 Tercera Parte, Página 109, bajo el rubro y textos siguientes[...].

Y a continuación cita el texto total de la jurisprudencia que los comuneros habían hecho valer en sus agravios. Continua la sentencia:

Las consideraciones precedentes, ponen de manifiesto el derecho de propiedad de la comunidad accionante respecto de la superficie de 
7,488-80-00 hectáreas, que les fueron confirmadas y tituladas por Resolución Presidencial del diez de marzo de mil novecientos cincuenta y cuatro, así como que las superficies de 911-00-00 hectáreas y 579-00-00 hectáreas, que les fueron reconocidas y tituladas de manera complementaria mediante Resoluciones Presidenciales del ocho de abril de mil novecientos setenta y veintisiete de julio de mil novecientos ochenta y siete, respectivamente, asimismo, que en la parte norte dentro de la poligonal de la confirmación y titulación de bienes comunales, existe una superficie de 1,424-94-28 hectáreas, que corresponde al vaso de almacenamiento y zona de protección de la presa "Plutarco Elías Calles" a cargo de la Comisión Nacional del Agua, que le fue afectada a la comunidad sin mediar el procedimiento expropiatorio respectivo.

El segundo punto resolutivo manda que, "ante la imposibilidad material de restituir [...] la superficie reclamada", se condena a los demandados al pago de la superficie de 1'455-89-82 hectáreas, afectada a la comunidad accionante por la construcción de la presa "Presidente Plutarco Elías Calles".

La sentencia establece un criterio para calcular el pago, el cual los comuneros no aceptan, razón por la cual interponen recurso de revisión. Las dependencias federales condenadas al pago en la sentencia, también se van a la revisión, impugnando la totalidad de la sentencia. El Tribunal Superior Agrario, dicta resolución en el recurso de revisión número 565/2007-01, el 21 de febrero de 2008, confirmando la sentencia recurrida en todos sus términos, y por lo tanto no estableciendo modificación alguna en lo resuelto por el Tribunal Unitario Agrario.

Ante esto, tanto los comuneros como la Federación, han recurrido al Amparo Directo, en los términos y con las pretensiones establecidas en el recurso de revisión. Este amparo está en estudio en el Segundo Tribunal Colegiado en materia Administrativa en la Ciudad de México.

\section{Final con esperanza, a pesar de todo}

Hace unos días apareció en los diarios locales una declaración del delegado de la Secretaría de la Reforma Agraria en Aguascalientes, 
Obed Gerardo Arellano Gutiérrez, diciendo que "va para largo la expropiación de la presa Calles"; y que ahora el asunto está en manos de un Tribunal Colegiado de Circuito, que será el que defina el monto del pago (El Heraldo, Aguascalientes, 15 de octubre de 2008, p. 3).

Nosotros decimos, y los comuneros de seguro piensan, que por largo que sea, ya no será tanto. Creemos que estamos al final del camino. Carolina Castro cuenta:

Todos estábamos tristes, también nosotros los pobres. Cuando vimos que el agua empezaba a llegar a nuestras parcelas a nuestras casas, a todos los rincones del pueblo, se volvió tristeza aquella alegría del progreso que nos dijeron dejaría la construcción de la presa (CASTRO PADILLA, [19-?]).

Ahora, a más de 80 años, los descendientes de aquellos que vieron como la Presa cubrió totalmente con sus aguas el pueblo y las parcelas de cultivo; ahora, digo, esos descendientes esperan, por fin, justicia.

\section{Referencias}

CASTRO PADILLA, C. Bajo las agua crecen nuestros recuerdos. [s.l.]: [s.n.], [19--?]. SERRANO, J. G. Apuntes para la historia de San José de Gracia. Aguascalientes: Instituto Cultural de Aguascalientes, 1992. Documento de San José de Gracia.

Recibido: 23/09/2009

Recebido: 23/09/2009

Aprobado: 02/11/2009

Aprovado: 02/11/2009 